\title{
Regimes de informação, agentes governamentais e tipologias de informação: o monitoramento da implementação da Convenção 182 da Organização Internacional do Trabalho
}

\author{
Pedro Alves Barbosa Neto ${ }^{I}$ \\ Judson Daniel Oliveira da Silva ${ }^{\text {II }}$ \\ IUniversidade Federal do Rio Grande do Norte, Natal, RN, Brasil. \\ Professor Adjunto do Departamento de Ciência da Informação. \\ Vice-coordenador do Programa de Pós-Graduação em Gestão \\ da Informação e do Conhecimento. Doutor em Ciência da Informação \\ pela Universidade Federal de Minas Gerais.

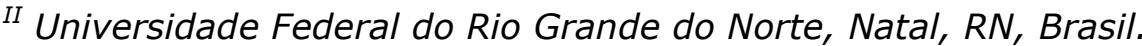 \\ Bacharel em Biblioteconomia.
}

http://dx.doi.org/10.1590/1981-5344/3536

O artigo correlaciona os conceitos de Regimes de Informação com os procedimentos desenvolvidos no processo de monitoramento da implementação das Normas Internacionais do Trabalho propostas pela Organização Internacional do Trabalho (OIT). Especificamente observa-se a Convenção 182 da OIT, que porta sobre a Erradicação das Piores Formas do Trabalho Infantil. São apresentados conceitos que subsidiam a compreensão dos Regimes Internacionais de Direitos Humanos e de seus respectivos Regimes de Informação. São apresentadas as características do procedimento de monitoramento da implementação das Normas Internacionais do Trabalho, com foco nas práticas informacionais que o subsidiam. Por fim, são analisadas as tipologias e os processos informacionais verificados nos procedimentos de monitoramento da Convenção 182, em países do continente americano. Conclui-se que embora $o$ Regime Internacional de Direitos Humanos, aqui representado pela OIT, objetive estabelecer um padrão de comportamento informacional equalizado para todos os seus Estados-membros, existe uma patente variação dos 
níveis de colaboração por parte de cada Estado-nacional. Conclui-se que os Regimes Internacionais apresentam importância indubitável na consolidação de um contexto de proteção social e de preservação de princípios e garantias fundamentais, contudo, os seus respectivos Regimes de Informação dependem em última instância da vontade política dos contextos nacionais em colaborar de modo adequado com o Regime.

Palavras chave: Regimes de Informação; Regimes Internacionais; Monitoramento Informacional; Organização Internacional do Trabalho; Piores Formas do Trabalho Infantil

\section{Information Regimes, governmental agents and information typologies: monitoring the implementation of 182 ILO Convention}

This article correlate the concepts of Information Regimes with the procedures developed in the process of monitoring the implementation of the International Labor Standards proposed by the International Labor Organization (ILO). The 182 ILO Convention, which deals with the Eradication of the Worst Forms of Child Labor, is the guiding object. From the theoretical point of view are presented concepts and definitions that subsidize the understanding of the International Human Rights Regimes and their respective Information Regimes. In addition, the characteristics of the monitoring procedure of the implementation of the International Labor Standards are presented, focusing on the informational practices that support their full development. Finally, the typologies and informational processes verified in the monitoring procedures of Convention 182 in countries of American continent are analyzed. As a result, it can be seen that although the International Human Rights Regime, represented by the International Labor Organization, aims to establish a standard of informational behavior equalized for all its member states in the implementation of the International Norms, there is a patent variation of levels of collaboration by each national State. It is understood that the International Regimes present 
undoubted importance in the consolidation of a context of social protection and preservation of fundamental principles and guarantees, however, their respective Information Regimes depend ultimately on the political will of the national contexts to collaborate in an appropriate manner with the Regime.

Keywords: Informational Regimes; International Regimes; Informational Monitoring; International Labor Organization; Worst Forms of Child Labor

Recebido em 19.05.2018 Aceito em 20.11.2018

\section{Introdução}

O artigo tem como objetivo correlacionar os conceitos de Regimes de Informação com os procedimentos desenvolvidos no processo de monitoramento da implementação das Normas Internacionais do Trabalho propostas pela Organização Internacional do Trabalho (OIT). Tem-se como objeto norteador a análise da Convenção 182 da OIT, que porta sobre a Erradicação das Piores Formas do Trabalho Infantil.

A informação desempenha um papel vital para todas as atividades desenvolvidas pela Organização Internacional do Trabalho. Assim como em outras organizações, a capacidade de se basear em informações do ambiente interno e externo para organizar e direcionar os processos de atuação é um fator determinante no desempenho das ações desenvolvidas pela OIT.

A OIT é guiada pelo espírito do diálogo social e apresenta como tarefas principais a elaboração, a adoção e o controle da aplicação das Normas Internacionais do Trabalho. Por ser assim, torna-se inevitável pensar que seus integrantes estratégicos, envolvidos nestas tarefas, necessitem de informação para se apoiar no processo de desenvolvimento de suas atividades.

Assim o que se pretende, em última instância, é demonstrar a relevância da constituição de um aparato teórico e empírico, no campo da Ciência da Informação, para compreender como se constituem regimes e fluxos de informação que são fundamentais para garantir o monitoramento de convenções internacionais de direitos humanos, como é o caso da Convenção 182 da OIT.

Para responder a problemática norteadora da pesquisa empreendeuse, além de pesquisa bibliográfica para subsidiar a construção teórica do trabalho, pesquisa documental tendo como fontes principais os relatórios informativos produzidos e enviados pelos Estados-nacionais para o monitoramento da implementação da Convenção 182 pelo Comitê de Peritos da Organização Internacional do Trabalho. A amostra do estudo foi composta por cinco países do continente americano que apresentam 
diferentes indicadores socioeconômicos e de desenvolvimento humano, com isso, buscou-se a consecução de uma amostra heterogênea e representativa dos países que compõem as Américas.

Os Regimes Internacionais de Direitos Humanos configuram-se como resultado de intenso diálogo e consenso entre nações, povos e culturas e desenvolvem ações que visam garantir que os seres humanos coexistam em paz. Apesar de sua interdisciplinaridade constitutiva, esses complexos Regimes ainda padecem de maior compreensão acerca de sua potencialidade enquanto objeto de estudos em muitos campos científicos, dentre os quais se inclui a Ciência da Informação.

Considerando esta lacuna, este trabalho vem oferecer uma abordagem emergente que posiciona os Regimes Internacionais de Direitos Humanos na centralidade de um debate que tem como pano de fundo a questão informacional. Desvelar aspectos da informação na esfera desses Regimes se faz urgente, dado o momento histórico-social vivenciado hoje. Atualmente a sociedade se encontra mais conectada por meio de redes e ambientes de interação que habilitam a formação e o desenvolvimento de um, cada vez mais comum, "cidadão do mundo". Cidadão este capaz de participar como protagonista ativo do Regime Internacional mencionado anteriormente. Daí a necessidade precisa de uma compreensão dos Regimes Internacionais de Direitos Humanos sob a ótica da informação. Já que, é através da informação que o cidadão se manifesta e desempenha seu papel no Regime.

Na primeira parte do artigo, são apresentados conceitos e definições que subsidiam a compreensão dos Regimes Internacionais de Direitos Humanos e de seus respectivos Regimes de Informação, entendendo aspectos das Políticas de Informação e dos atores Públicos de informação que determinam os fluxos informacionais por eles propostos.

$\mathrm{Na}$ segunda parte são apresentadas as características do procedimento de monitoramento da implementação das Normas Internacionais do Trabalho, com foco nas práticas informacionais que subsidiam o seu pleno desenvolvimento.

$\mathrm{Na}$ terceira parte, são analisadas as tipologias e os processos informacionais verificados nos procedimentos de monitoramento da Convenção 182, sobre as Piores Formas do Trabalho Infantil, em países do continente americano, estabelecendo um vínculo direto com o aporte teórico apresentado na primeira e segunda partes do trabalho.

\section{Regimes Internacionais de Direitos Humanos e Regimes de Informação}

Ao entender o papel fundamental da informação em todas as atividades centrais desenvolvidas pela Organização Internacional do Trabalho, em que dispositivos informacionais provenientes de instâncias e atores com características muito diversas são contemplados, observa-se o delineamento de um Regime Internacional que pode ser determinado por 
duas esferas distintas: o da normativa internacional acerca dos Direitos Humanos vinculados ao mundo do trabalho; e o da informação.

A esfera internacional de regulamentação normativa no âmbito dos Direitos Humanos é, sobremaneira, orientada por regimes que determinam padrões de condutas e estabelecem normas e diretrizes que devem ser obedecidas pelos Estados nas relações com seus cidadãos. Etimologicamente a ideia de Regime se refere a um completo sistema político e social que apresenta um contexto com características que tendem a ser naturalmente obedecidas pelos atores que o integram.

Regime é definido por Krasner (1982) como "normas e procedimentos de tomada de decisão" aceitos por atores institucionais para regular um campo ou uma área. Na seara internacional dos Direitos Humanos, os Estados aceitam certas normas ou procedimentos, a priori restritivos, legitimando-os, e, assim, substituindo parcialmente a soberania nacional original pela autoridade internacional. A partir dessa perspectiva, os regimes internacionais requerem renúncias limitadas da soberania nacional em determinadas áreas como preço a ser pago na redução da anarquia internacional.

Como é esclarecido por Krasner (1982) as formas de Regimes Internacionais não são mutuamente exclusivas, entretanto, a transferência de autoridade pode variar de forma, e causar uma notável variância de graus. Nesse sentido, numa proposta de categorização dos tipos de Regimes Internacionais existentes, Donelly (1986) indica que estes podem ser: Regimes de Normas Internacionais Autoritárias ${ }^{1}$; Regimes de Padrões Internacionais com possibilidades de exceções nacionais $^{2}$; Regimes de Guidelines Internacionais ${ }^{3}$; e Regimes de Padrões Nacionais ${ }^{4}$. Essas categorias, segundo o autor apresentam variação de força na medida em que compelem de modo diferenciado o Estadonacional a se conformar com as normativas por elas estabelecidas.

Os Regimes Internacionais habilitam uma série de possibilidades de tomada de decisão no cenário internacional de Direitos Humanos. Além da criação de normas internacionais, outras atividades podem ser verificadas como características determinantes no âmbito dos Regimes, estas se configuram, por exemplo, como fortalecimento de normas internacionais já existentes; implementação de normas internacionais e promoção destas normas. Esse argumento corrobora a perspectiva de Donelly (1986) no que diz respeito a variâncias dos graus de força dos Regimes Internacionais de Direitos Humanos.

Analisando as categorias de Regimes Internacionais de Direitos Humanos e as modalidades de Tomadas de Decisão por eles fomentadas,

Nessa modalidade verifica-se a existência de padrões internacionais vinculativos, geralmente aceitos pelos Estados como tal.

2 Nessa categoria, as normas geralmente são vinculativas e em alguns casos permitem que os Estados façam reservas no ato da ratificação de um tratado ou convenção internacional.

3 Caracterizam-se por ser padrões internacionais que não são vinculativos, mas são respeitados pelos Estados. Guidelines podem apresentar um forte alcance e regras detalhadas.

4 São caracterizados pela ausência completa de normas internacionais substanciais. Não há concessão de propriedades da soberania nacional. 
Donelly (1986) entende que as atividades de implementação das normas internacionais envolvem posturas nacionais distintas. Todavia, uma característica constante se dá na existência de modelos de monitoramento da implementação das normas, muito embora estes apresentem variações de abrangência e de sofisticação.

Nesse sentido, ao entender a implementação das Normas Internacionais do Trabalho como parte determinante para a conformidade dos Estados-nacionais para com o Regime Internacional, percebe-se que os atores e as instâncias governamentais inseridos nessa tarefa emergem como elementos decisivos para composição e entrelaçamento dos elos componentes do Regime.

Donelly (1986) acrescenta que se por um lado o estabelecimento de normas fica a cargo dos Regimes Internacionais, por outro, a decisão de implementá-las continua largamente nacional. Nesse sentido, esclarece-se que o princípio procedimental central do Regime Internacional contemporâneo é a jurisdição nacional em relação às questões de Direitos Humanos. Todavia, percebe-se que a performance nacional é assunto de supervisão e de monitoramento internacional.

Como sublinham Frota e Barbosa Neto (2014) os Regimes Internacionais de Direitos Humanos se valem, de modo majoritário, de informações providas pelos Estados-membros como ferramenta importante de monitoramento da implementação de seus instrumentos normativos, sejam eles tratados ou convenções. Através de procedimentos diversos os Regimes, sejam eles universais ou regionais, geralmente convocam os seus Estados-membros a elaborarem periodicamente relatórios informativos, com foco principal no provimento de informações acerca da situação prática, legislativa e social das questões determinantes gestadas pelos tratados e convenções internacionais. Nesse contexto, a Ciência da Informação, por meio de sua estrutura teórico-metodológica pode confluir para uma compreensão alargada das dimensões da informação no âmbito dos Regimes Informacionais de Direitos Humanos, especificamente no que diz respeito às Organizações Internacionais componentes do Regime.

Essa conduta informacional que envolve diferentes atores, instâncias e perspectivas contribui para a formatação de fluxos informacionais bem definidos pelos quais as informações percorrem desde a sua elaboração até o seu uso pelos Comitês e Comissões responsáveis pelo controle e monitoramento nos âmbitos dos Regimes Internacionais.

Na concepção de Braman (2004), Regime pode ser definido como um quadro normativo e regulatório internacional que é menos rígido e menos formal que o sistema jurídico, mas que serve para ligar todas as partes envolvidas em determinada matéria de interesse. Ele oferece definições operacionais, estabelece uma hierarquia de valores e define regras de negociação e procedimentos. Um regime inclui normas éticas e comportamentos, práticas culturais, hábitos, estruturas de conhecimento, formas organizacionais, processos decisórios individuais e do setor 
privado, tecnologias, leis formais e regulamentações de instituições oficialmente reconhecidas.

A autora afirma que em contraposição à rigidez das leis formais, a noção de Regime incorpora características que melhor atendem à necessidade de tratamento político dos processos de informação acoplados ao contexto, cuja natureza é extremamente dinâmica e transformadora.

No contexto da Ciência da Informação uma importante contribuição é oferecida por González de Gómez (2012) quando articula os elementos conceituais centrais do Regime de Informação proposto por Braman (2004) e Frohmann (1995). Neste contributo, além de evidenciar os compostos nucleares do Regime de Informação, Gónzalez de Gomez sinaliza para uma divergência acerca da localização das políticas de informação na esfera dos regimes segundo a perspectiva dos dois autores supramencionados.

Frohmann (1995) assevera que o regime de informação despontaria como uma alternativa teórica aos estudos das políticas de informação, entendidos por ele como um reducionismo geralmente praticado no âmbito da Ciência da Informação. Ao se entender as políticas de informação como uma classe das políticas governamentais e, mais especificamente como uma estrutura normativa referente aos documentos governamentais, as políticas de informação tenderiam a desconsiderar esferas sociais determinantes para sua formação como seus produtores e atores sociais por elas afetados. Daí a importância de um conceito mais amplo e mais abrangente como o regime de informação.

Para Braman (2004) a formação do regime seria o processo pelo qual novas formas políticas emergem fora do campo da política. A política de informação se daria quando um fator interno ou externo do assunto em questão dependesse de transformações jurídicas ou regulamentares; no caso da política de informação temas como inovação tecnológica e os processos da globalização emergiriam como fatores particularmente importantes para estimular a transformação do regime global das políticas de informação.

Assim, tendo como base os apontamentos dos conceitos de regime de informação apresentados e as suas conexões teórico-práticas com as políticas de informação, destaca-se a necessidade inequívoca de regimes internacionais de informações sobre direitos humanos que reflitam a realidade de seus Estados-membros, de modo holístico, avançando na compreensão de todos os produtores e afetados pela implementação e pelo cumprimento de seu conjunto normativo.

Uma série de variáveis aparece, então, como elementos basilares para compreensão dessa interação dialética que se dá entre os Estadosnacionais e o Regime Internacional de Direitos Humanos. Destaca-se aqui como elementos desta interação: as políticas de informação e os agentes públicos de informação. 
Essa abordagem é corroborada por Magnani e Pinheiro (2011) quando afirmam que o foco na relação entre os atores- Agentes Públicos de Informação- é um aspecto valioso da ótica dos regimes internacionais, porque reúne elementos discursivos, normativos e culturais importantes para a análise das políticas de informação. É o caso, por exemplo, dos bens e serviços de informação que não aparecem na forma tangível, mas que estão incorporados nas relações, como os recursos disponíveis nas redes de interação social e as produções colaborativas de informação, o que reflete diretamente a prática normativa das Organizações Internacionais de Direitos Humanos. Nesse sentido, os fluxos informacionais originados pelos Regimes visam, sobretudo, suprir necessidades de informação orientadas seja para a ação ou para a construção de novos conhecimentos.

Conforme Barreto (2001), o fluxo informacional é caracterizado pela transferência de informação entre os estoques ou espaços de informação e os usuários. O fluxo da informação deve ter como foco a transferência de recursos informacionais e a apropriação do conteúdo informacional e ser orientado pela análise do uso da informação pelos usuários. Essa perspectiva, proposta por Barreto (2001) é considerada relevante para a análise de fluxos informacionais constituídos a partir de Regimes Internacionais de Direitos Humanos. Estes fluxos informacionais são instaurados pelas Organizações Internacionais de Direitos Humanos na construção e manutenção de um regime de informação.

Conforme sublinhado por Torobin (2000) o regime de informação proposto pelo sistema de monitoramento da implementação das Normas Internacionais do Trabalho da OIT, é considerado atualmente o mais sofisticado sistema de controle dentre as Organizações Internacionais de Direitos Humanos. Este sistema será pormenorizado a seguir.

\section{A Organização Internacional do Trabalho e o processo de monitoramento da implementação das normas}

A Organização Internacional do Trabalho (OIT), como elucida Torobin (2000), foi criada em 1919, com o objetivo de eliminar a injustiça, a miséria e as privações ao redor do mundo. Posteriormente outras questões de caráter mais geral foram inseridas no domínio de atuação da OIT, entretanto, todas essas questões sempre estiveram vinculadas às políticas sociais e aos Direitos Humanos.

O autor explica que por mais que a OIT desempenhe tarefas com características diversas, a função normativa é sem dúvida a principal atividade da Organização Internacional do Trabalho. Os instrumentos pelos quais a OIT estabelece as Normas Internacionais do Trabalho são as Convenções e as Recomendações. Esses instrumentos são resultado de um diálogo internacional coletivo tripartite, do qual são convidados a participar representantes dos governos, dos empregadores e dos empregados de todas as partes do mundo. 
As convenções da OIT, por um lado, detêm o status de tratados internacionais $\mathrm{e}$, por ser assim, podem ser ratificadas pelos Estadosmembros. Por outro lado, as recomendações são consideradas guidelines de caráter facultativo, para apoiar uma melhor implementação das convenções da OIT.

As convenções da OIT são Tratados Internacionais que, ao serem ratificadas pelos Estados-membros, criam obrigações jurídicas explícitas. Ao contrário da prática normativa da Organização das Nações Unidas e de outras agências especializadas, as convenções da OIT não permitem ressalvas. Isso significa que, para ratificar alguma convenção desta Organização, os seus Estados-parte devem estar inteiramente de acordo com as disposições nelas encontradas.

As normas da Organização Internacional do Trabalho são, conforme Torobin (2000), verdadeiros modelos universais em matéria de Direitos Humanos com foco específico nas condutas e condições verificadas no mundo do trabalho. Elas têm por objetivo melhorar concretamente as condições e práticas no ambiente de trabalho, no âmbito de todos os países do mundo.

Como constata Hilton (2003), a avaliação da implementação de normas internacionais por parte dos comitês responsáveis é caracterizada por três níveis: perspectiva legal, performance do governo e resultados gerais. Para tanto, o instrumento de apoio ao monitoramento ou ao controle da aplicação no âmbito local são relatórios baseados tanto em informações qualitativas quanto em dados quantitativos.

No que diz respeito especificamente à Organização Internacional do Trabalho, nota-se que as tipologias das informações oferecidas pelos Estados-membros ao Comitê de Peritos, órgão que se ocupa do controle da aplicação das normas internacionais, é questionável, pois apresenta profundo grau de instabilidade e de variabilidade. Além disso, as metodologias para mensurar o grau de implementação de determinada convenção ou recomendação se encontram em constante desenvolvimento.

O atual sistema de controle ordinário da implementação das normas internacionais proposto pela OIT é exclusivamente baseado em informações produzidas pelos Estados-membros. Desse modo, questões relacionadas à natureza, forma e conteúdo dessas informações, vinculamse diretamente ao interesse desse Estado-membro em cooperar com o sistema de controle.

Ressalta-se, de acordo com Barzotto (2007), que, com a crescente especialização técnica da OIT e o aumento do número de convenções e recomendações adotadas e, com a adoção da Declaração de Princípios e Direitos Fundamentais do Trabalho de 1998, estabeleceu-se que os relatórios contendo informações sobre as oito convenções fundamentais e sobre as quatro convenções consideradas como prioritárias passaram a ser solicitados a cada dois anos. Por outro lado, os relatórios acerca das 
demais convenções passaram a ser enviados a cada cinco anos como assevera a Declaração de Princípios e Direitos Fundamentais do Trabalho.

Existe por parte do Comitê de Peritos um esforço para o estabelecimento de um padrão, o qual os países devem observar para a sistematização das informações contidas nos relatórios oficiais. Para a composição do primeiro relatório, as informações são solicitadas tendo como base os artigos constantes nas convenções ou recomendações. Isso significa que, a cada artigo, individualmente, o Comitê solicitará informações sobre sua aplicação na legislação e na prática. O caráter das informações solicitadas (qualitativo ou quantitativo) estará diretamente vinculado ao tema do qual se ocupa determinada convenção ou recomendação. Para os relatórios subsequentes o Comitê de Peritos realiza demandas diretas por informações acerca de temas considerados de relevância específica para a compreensão do nível de implementação das normas internacionais do trabalho. Essas demandas diretas por informações são inseridas em documentos denominados "Comentários Resposta".

Uma questão importante sobre as informações que compõe os relatórios é a sua vulnerabilidade em relação aos atores de informação pública engajados na coleta de dados, na produção, na sistematização e no envio dessa informação. As etapas da produção e de sistematização da informação são as que, sem dúvida, apresentam características de maior fragilidade. Essa fragilidade se dá na medida em que as informações refletem o ponto de vista das pessoas responsáveis pela sua produção e dos organismos que as vinculam, podendo apresentar vieses, o que, sem dúvida, não corresponde aos critérios de imparcialidade e neutralidade.

Por ser assim, as associações de empregados e empregadores mais representativas de cada Estado-membro são convocadas a integrar o grupo dos atores envolvidos nos procedimentos realizados pela Organização Internacional do Trabalho, completando as instâncias que formam o fluxo informacional. Isso porque é solicitado aos governos que enviem cópias dos relatórios a essas associações, para que seus representantes possam tecer comentários sobre as informações inseridas originalmente pelo governo, podendo fornecer outras informações ou mesmo impedir que determinadas informações controversas sejam enviadas ao Comitê de Peritos.

A essa prática se dá o nome de "controle social da informação", a que Frota e Barbosa Neto (2010) qualificam como um fenômeno que contribui para desmistificar o discurso jurídico produzido pelos produtores de informação e que estimula o exercício da atividade cidadã de um modo mais prático e político, em oposição a um modelo puramente técnico e econômico, como atualmente o é percebido.

Analisando os procedimentos jurídicos, administrativos e informacionais apresentados pela Organização Internacional do Trabalho observa-se que se trata de um regime que se aproxima do que Donelly (1986) qualifica como Regimes de Padrões Internacionais, em que pese a 
OIT não permita ressalvas de elementos dos seus textos normativos, suas normas são vinculativas e geram responsabilidade jurídica explícita.

Observa-se também no conjunto normativo ostentado pela OIT a existência de Guidelines Internacionais, na figura das Recomendações, contudo, faz-se necessário ressaltar que estes instrumentos não se encontram no centro da prática normativa da Organização Internacional do Trabalho, são muito antes documentos orientadores para uma melhor implementação das Convenções Internacionais, onde de fato reside o cerne da prática normativa.

Conforme mencionado anteriormente, os procedimentos informacionais acerca do monitoramento da implementação das normas internacionais do trabalho podem variar segundo um complexo conjunto de variáveis como, por exemplo: o contexto nacional do Estado-membro e; sobre qual convenção está incidindo o processo de monitoramento. Neste sentido, com o objetivo de aferir, empiricamente essa realidade, elencou-se uma amostra de cinco países do continente americano, com foco em entender os processos informativos relacionados ao monitoramento da Convenção 182- umas das oito convenções fundamentais da OIT- que porta sobre a Erradicação das Piores formas do trabalho infantil, tema de incontestável relevância social em nível global.

\section{Monitoramento da implementação e tipologias informacionais no contexto americano: o caso da convenção 182, sobre a erradicação das piores formas do trabalho infantil no continente americano}

A Convenção 182 da Organização Internacional do Trabalho tem como foco a proteção de todos os indivíduos menores de dezoito anos. Ao se tornarem parte da Convenção 182, os Estados se comprometem a estabelecer metas e planos de ação com vistas a abolir imediatamente e de modo permanente as seguintes categorias de atividades:

a) todas as formas de escravidão ou práticas análogas à escravidão, tais como a venda e tráfico de crianças, a servidão por dívida e condição de servo e o trabalho forçado ou obrigatório de crianças para serem utilizadas em conflitos armados:

b) a utilização, o recrutamento ou a oferta de crianças para a prostituição, a produção de pornografia ou atuações pornográficas;

c) a utilização, recrutamento ou a oferta de crianças para a realização de atividades ilícitas, em particular a produção e o tráfico de entorpecentes, tais como definidos nos tratados internacionais pertinentes; 
d) o trabalho que, por sua natureza ou pelas condições em que é realizado, é suscetível de prejudicar a saúde, a segurança ou a moral das crianças. (ORGANIZAÇÃO INTERNACIONAL DO TRABALHO, 1999).

A Convenção 182 integra o rol das convenções fundamentais da OIT. Em função disso, os relatórios com informações sobre a implementação dessas convenções no âmbito dos Estados-parte devem ser submetidos à apreciação pelo Comitê de Peritos com periodicidade bianual.

Diante da proposta inicial deste trabalho, foi designada uma amostra de cinco países do continente americano, tendo como base para a composição de uma amostra heterogênea sob os aspectos, econômicos, sociais, políticos, administrativos e culturais. São esses os países: Bolívia, Brasil, Chile e Costa Rica e Estados Unidos.

Os quadros abaixo apresentam características das variáveis escolhidas para a seleção da amostra.

QUADRO 1: Indicadores socioeconômicos dos Estados signatários da Convenção 182

\begin{tabular}{|c|c|c|c|c|}
\hline País & $\begin{array}{c}\text { Índice de } \\
\text { Desenvolvimento } \\
\text { Humano } 2013\end{array}$ & $\begin{array}{c}\text { Produto } \\
\text { Interno } \\
\text { Bruto } 2013 \\
\text { (per } \\
\text { capita) }\end{array}$ & $\begin{array}{l}\text { Paridade do } \\
\text { Poder } \\
\text { Aquisitivo } \\
2011 \text { (per } \\
\text { capita) }\end{array}$ & $\begin{array}{c}\text { Densidade } \\
\text { Demográfica } \\
(2012)\end{array}$ \\
\hline Bolívia & Mediano - 0.675 & $\$ 2,532,00$ & $\$ 5.099,00$ & $9 \mathrm{hab} / \mathrm{km}^{2}$ \\
\hline Brasil & Elevado - 0.730 & $\$ 12.118,00$ & $\$ 12.118,00$ & $23.7 \mathrm{hab} / \mathrm{km}^{2}$ \\
\hline Chile & $\begin{array}{l}\text { Muito elevado - } \\
0.819\end{array}$ & $\$ 16.273,00$ & $\$ 19.475,00$ & $23 \mathrm{hab} / \mathrm{km}^{2}$ \\
\hline Costa Rica & Elevado - 0.773 & $\$ 9.672,00$ & $\$ 12.606,00$ & $84 \mathrm{hab} / \mathrm{km}^{2}$ \\
\hline EUA & $\begin{array}{l}\text { Muito elevado - } \\
0.937\end{array}$ & $\$ 52.839,00$ & $\$ 52.839,00$ & $34.2 \mathrm{hab} / \mathrm{km} 2$ \\
\hline
\end{tabular}

Fonte: elaboração própria (2015)

QUADRO 2: Estruturas administrativas dos Estados signatários da Convenção 182

\begin{tabular}{|c|c|c|}
\hline País & Tipo de governo & $\begin{array}{l}\text { Divisão político } \\
\text { geográfico }\end{array}$ \\
\hline Bolívia & República social unitária & 9 departamentos \\
\hline Brasil & Republica federalista & $\begin{array}{c}26 \text { estados e } 1 \text { distrito } \\
\text { federal }\end{array}$ \\
\hline Chile & República & 15 regiões \\
\hline Costa Rica & República democrática & 7 províncias \\
\hline EUA & República federativa presidencialista & 50 estados e 1 distrito \\
\hline
\end{tabular}


Como se pode perceber há uma notável heterogeneidade no que diz respeito aos indicadores socioeconômicos na amostra selecionada. Além disso, optou-se por elencar Estados que ostentassem Regimes de Governo distintos. Isto porque, em muitos casos, as competências jurídicas partilhadas entre o governo central e as unidades que compõem o Estadonação impactam diretamente o processo de produção de informação e a sua posterior sistematização pela autoridade responsável por implementar a Convenção 182 no âmbito do Estado-nacional.

Numa análise preliminar objetivou-se verificar se há adequação dos Estados-membros frente à solicitação do envio periódico dos relatórios oficiais. Assinala-se que todos os países integrantes da amostra são signatários da Convenção N.182, e por ser assim, se comprometeram junto à Organização Internacional do Trabalho a enviar relatórios com informações a cada dois anos. Ressalta-se que o período observado neste estudo compreende o ano do envio do primeiro relatório tendo como base o ano de ratificação de cada Estado até o ano de 2018. O Quadro 2 oferece um panorama do envio das informações.

QUADRO 3: Conformidade com a periodicidade de envio de informações pelos governos.

\begin{tabular}{|c|c|c|c|}
\hline Países da amostra & $\begin{array}{c}\text { Ano da } \\
\text { Ratificação }\end{array}$ & $\begin{array}{c}\text { Conformidade de } \\
\text { envio }\end{array}$ & $\begin{array}{c}\text { Participação de } \\
\text { parceiros sociais }\end{array}$ \\
\hline Bolívia & 2003 & $\begin{array}{c}\text { Não }(2005,2007,2010, \\
2014 \text { e 2017) }\end{array}$ & Sim \\
\hline Brasil & 2000 & $\begin{array}{l}\text { Não }(2002,2004,2006, \\
2008,2010 \text { e } 2015)\end{array}$ & Sim \\
\hline Chile & 2000 & $\begin{array}{c}\text { Não }(2002,2004,2006, \\
2008,2010,2012, \\
2017)\end{array}$ & Sim \\
\hline Costa Rica & 2001 & $\begin{array}{c}\text { Não }(2003,2005,2007, \\
\text { 2009, 2011, 2013, } \\
2017)\end{array}$ & Sim \\
\hline EUA & 1999 & $\begin{array}{c}\text { Não }(2001,2013 \mathrm{e} \\
2014,2016)\end{array}$ & Sim \\
\hline
\end{tabular}

Fonte: elaboração própria (2015)

Conforme apresentado pelo Quadro acima, tem-se que todos os países da amostra se encontram em desconformidade com a obrigação de enviar a cada dois anos após a ratificação relatórios contendo informações acerca da implementação da Convenção 182. Entretanto, é necessário dizer que embora haja uma desconformidade generalizada, alguns países submeteram relatórios com intervalos mais curtos do que outros. Destaca-se a frequência aproximada do ideal apresentada por Chile e Costa Rica. No que diz respeito ao caso estadunidense verifica-se uma patente desconformidade com os prazos para envio das informações, uma vez que aquele país enviou o primeiro relatório em 2001, voltando a submeter informações nos anos de 2013, 2014 e 2016. É necessário frisar que muito embora o governo norte-americano não tenha cumprido com o dever de informar o Comitê de Peritos no período solicitado, associações de empregados e empregadores desempenharam esta função de modo 
salutar. Uma vez que essas associações encaminharam informações ao Comitê de monitoramento da implementação da Convenção mesmo que o Governo estadunidense não o tenha feito nos períodos previstos.

A Bolívia, conforme apresentado pelo quadro acima se encontra em desconformidade devido a atrasos nas três últimas remessas de informações para o Comitê de Peritos. Salienta-se, contudo, que estes relatórios foram encaminhados, ainda que de modo intempestivo.

O caso brasileiro, merece destaque, pois, o Brasil apresentou desde o início do processo de informação, visível conformidade com os prazos e exigências de envio de informações, todavia, desde o ano de 2015 o país não encaminhou novas informações ao Comitê de Peritos da Organização Internacional do Trabalho.

Para o desenvolvimento da segunda fase da análise, foram cunhadas categorias que agrupam seis tipologias de informações enviadas pelos Governos durante o processo de monitoramento em seus relatórios periódicos. Entende-se por tipologia informacional 0 agrupamento semântico de conteúdo informacional correspondente a um grupo temático de informações. O objetivo da elaboração e utilização das categorias informacionais é facilitar o entendimento a respeito do fluxo de informações para o monitoramento da implementação da Convenção estudada. Além disso, estas tipologias oportunizam a compreensão sobre a perspectiva do país com relação à erradicação das Piores Formas do Trabalho Infantil, na medida em que cada tipo de informação se vincula diretamente a determinadas esferas da administração pública governamental e, portanto, oferece indícios acerca da coleta, produção e sistematização da informação por parte dos agentes públicos.

O quadro a seguir sintetiza a dinâmica de cada um dos países componentes da amostra no que tange as tipologias informacionais ${ }^{5}$.

QUADRO 4: Tipologias informacionais enviadas pelos países no processo de monitoramento da implementação da Convenção 182

\begin{tabular}{|c|c|c|c|c|c|c|} 
País & $\begin{array}{c}\text { Mudanças na } \\
\text { Legislação }\end{array}$ & $\begin{array}{c}\text { Políticas } \\
\text { Públicas / } \\
\text { Programas }\end{array}$ & $\begin{array}{c}\text { Resultados } \\
\text { de ações } \\
\text { públicas }\end{array}$ & $\begin{array}{c}\text { Situações } \\
\text { Específica } \\
\text { s }\end{array}$ & $\begin{array}{c}\text { Informaçõe } \\
\text { s } \\
\text { Estatísticas }\end{array}$ & $\begin{array}{c}\text { Relatórios } \\
\text { Policiais }\end{array}$ \\
\hline Bolívia & Sim & Sim & Sim & Sim & Sim & Não \\
\hline Brasil & Sim & Sim & Sim & Não & Sim & Não \\
\hline Chile & Sim & Sim & Sim & Não & Sim & Não \\
\hline Costa Rica & Sim & Sim & Não & Não & Sim & Sim \\
\hline E.U.A. & Sim & Sim & Sim & Não & Sim & Sim \\
\hline
\end{tabular}

Fonte: elaboração própria (2015)

Ressalta-se que a pesquisa documental foi a técnica de coleta de dados eleita, e os relatórios periódicos enviados pelos Estados-parte foram as fontes documentais acessadas. Sublinha-se ainda que as informações foram coletadas junto ao Relatório Inicial e ao último Relatório enviado por cada Estadomembro. 
Como ilustrado pelo Quadro 4, no tocante às categorias das informações enviadas no âmbito do monitoramento da aplicação da Convenção n. 182, vigora o seguinte panorama informacional:

- Mudança na Legislação ${ }^{6}:$ Observa-se que todos os países da amostra obtiveram êxito no encaminhamento de informações acerca de alterações na estrutura legislativa nacional ou local para estabelecer conformidade com os dispositivos da Convenção 182.

- Políticas Públicas e Programas ${ }^{7}$ : Novamente todos os Estados-membros observados encaminharam informações acerca do estabelecimento de Políticas Públicas ou Programas de ação relacionados à aplicação prática do conteúdo da Norma Internacional em apreciação.

- Resultados de ações públicas ${ }^{8}$ : Como apresentado pelo Quadro 4 apenas a Costa Rica não proveu informações acerca dos resultados das ações públicas empreendidas. Os outros quatro países da amostra foram capazes de coletar e sistematizar informações acerca do impacto na realidade social dos programas e políticas implementados.

- Situações Específicas ${ }^{9}$ : Com relação a esta tipologia informacional percebe-se que apenas Bolívia encaminhou informações relacionadas a situações específicas, ou casos, em que as piores formas do trabalho infantil pudessem ser ilustradas. Os outros quatro países da amostra não informaram o Comitê de Peritos a respeito desta tipologia.

- Informações Estatísticas ${ }^{10}$ : Indica-se que todos os países estudados proveram informações de caráter estatístico ao Comitê de Peritos. Esse resultado orienta para um interesse, em alguma medida, das agências de estatísticas estatais em coletar, produzir e sistematizar informações de modo quantitativo acerca das disposições contidas na Convenção 182 da OIT.

- Relatórios Policiais/Tribunais ${ }^{11}$ : Conforme percebido, dois países da amostra enviaram informações vinculadas a esta tipologia ao Comitê de Peritos: Costa Rica e Estados

6 Essa categoria se refere exclusivamente a modificações ocorridas nas legislações nacionais com o objetivo de se adequarem às disposições contidas nas Convenções n. 182

7 Essa categoria se refere a programas ou políticas governamentais desenvolvidas pelos Estados com o objetivo de enfrentar as práticas vedadas pela Convenção n. 182.

8 Essa categoria se refere a informações qualitativas ou quantitativas que versem sobre resultados de ações públicas com o foco na erradicação das piores formas do trabalho infantil.

9 Essa categoria se refere a informações que relatem casos concretos e específicos de violações aos dispositivos contidos na Convenção n. 182.

10 Essa categoria se refere a dados estatísticos absolutos ou relativos - em porcentagem - acerca dos temas abordados pela Convenção.

11 Essa categoria se refere a informações oferecidas pelos Estados que sejam colhidas ou selecionadas a partir de relatórios policiais, tribunais ou de cortes de justiça nacionais. 
Unidos. É oportuno salientar, no que tange esta categoria, que países que oferecem este tipo de informações tendem a incutir uma perspectiva penalista acerca das crianças e adolescentes inseridas nas práticas consideradas como piores formas do trabalho infantil.

\section{CONSIDERAÇÕES FINAIS}

Seguem algumas considerações acerca dos países da amostra no intuito de oferecer um panorama individual do monitoramento da implementação da Convenção N0182 sobre as piores formas de trabalho infantil da Organização Internacional do Trabalho.

Notou-se que o governo da Bolívia foi capaz de enviar informações de todas as tipologias informacionais apresentadas no tópico 3 do estudo, com exceção de relatórios policiais. Consoante a isso, o primeiro relatório de monitoramento disponibilizado pela OIT em 2006, mostra que após a ratificação da Convenção 182 houve uma mudança na legislação penal do país, que criminalizou o ato de facilitar a venda ou tráfico de pessoas para entrada ou saída do território boliviano visando atividades análogas à escravidão, a exploração sexual de cunho comercial e a venda ou fornecimento ilegal de órgãos, tal mudança na legislação instituiu também um agravante penal para quando tais crimes forem cometidos contra crianças.

No caso do Brasil, observou-se nos relatórios uma carga informacional extensa na tipologia de políticas públicas e programas no processo de monitoramento da implementação da Convenção 182. Contudo, o governo não apresentou informações na tipologia relatórios policiais/tribunais. O que poderia significar que o país não apresenta perspectiva penalista com relação às crianças e adolescentes inseridos nas atividades consideradas como as piores formas de trabalho infantil. Tal pensamento é fortalecido pelo fato das informações relativas à tipologia mudanças na legislação mostrarem que a proibição a determinadas atividades consideradas como as piores formas de trabalho infantil segundo a OIT só ocorreu após a ratificação da referida convenção. Nesse sentido, destaca-se a tipificação penal do ato de produzir cenas teatrais, atrações para televisão ou filmes, fotos ou qualquer outra mídia utilizando crianças em cenas de sexo explícito realizada pela Lei 10.764 de 2003 que altera a Lei 8.069 de 1990- que dispõe sobre o Estatuto da Criança e do Adolescente e dá outras providências.

Os relatórios enviados pelo governo do Chile proveram uma carga considerável de informações na tipologia políticas públicas e programas. Destaca-se, nessa tipologia, a criação de um banco de dados que é alimentado tanto com as legislações nacionais que estipulam a lista das piores formas de trabalho infantil quanto com demais informações relativas ao trabalho infantil. Contudo, nota-se a ausência de informações 
na tipologia relatórios policiais e tribunais e uma baixa ocorrência de informações da tipologia mudanças na legislação.

A análise dos relatórios da Costa Rica mostrou que a única tipologia informacional que não foi apresentada nos relatórios do governo foi a de situações específicas. Essa tipologia abarca informações sobre casos concretos e específicos de violações às normas constantes na Convenção 182. Seguindo a tendência geral dos relatórios dos demais países, notouse um volume considerável de informações na tipologia políticas públicas e programas. Destaca-se a elaboração do documento intitulado "Atividades perigosas e insalubres para jovens trabalhadores", que examina a possibilidade de determinar quais atividades podem entrar na lista de trabalhos proibidos às pessoas com menos de 18 anos de idade.

Os relatórios dos E.U.A. apresentaram uma baixa quantidade de informação quando comparados com os relatórios dos demais países da amostra. Contudo, embora eles tenham sido sucintos, apresentaram informações de todas as tipologias solicitadas pela OIT com exceção de situações específicas. Nos relatórios enviados pelo governo, se notou a predominância de informações da tipologia políticas públicas/programas, assim como os demais países da amostra. Destaca-se, nas informações dessa tipologia, o acordo realizado entre o Instituto Nacional de Segurança Ocupacional e o Departamento do Trabalho dos E.U.A. para conduzir pesquisas sobre riscos de saúde e segurança para crianças, com ênfase em assuntos relevantes as regulamentações de trabalho infantil.

Observando os dados apresentados a partir do contexto interno nota-se a impossibilidade de encontrar em qualquer um dos países da amostra um quadro em que o país signatário apresentou em seus relatórios informações de todas as tipologias solicitadas pela OIT. Portanto, se torna necessário analisar os relatórios, enviados por cada país, em caráter exaustivo para poder inferir a possível incapacidade de produção de informações em determinadas tipologias.

Destaca-se o fato de encontrar nos contextos boliviano, brasileiro e chileno a ausência de informações na tipologia relatórios policiais e tribunais, isto porque informações desse cunho podem ser observadas como uma possível constatação de aplicações práticas das vedações impostas pelas convenções e tratados internacionais.

A partir dos dados coletados e analisados é possível perceber que muito embora o Regime Internacional de Direitos Humanos aqui representado pela Organização Internacional do Trabalho, objetivar estabelecer um padrão de comportamento informacional equalizado para todos os seus Estados-membros no que tange o procedimento de monitoramento da implementação das Normas Internacionais, existe uma patente variação dos níveis de colaboração por parte de cada Estadonacional. Nesse sentido, entende-se que os Regimes Internacionais apresentam importância indubitável na consolidação de um contexto de proteção social e de preservação de princípios e garantias fundamentais, contudo, os seus respectivos Regimes de Informação dependem em 
última instância da vontade política dos contextos nacionais em colaborar de modo adequado com o Regime. Por fim, entende-se os produtos de informação envolvidos nesse contexto das relações internacionais como elementos definidores da efetivação dos objetivos propostos pelo Regime Internacional.

\section{Referências}

BARRETO, Aldo de Albuquerque. O tempo e o espaço da Ciência da Informação. Transinformação, Campinas, v. 14, n. 1, p.17-24, jun. 2001.

BARZOTTO, Luciane Cardoso. Direitos humanos e trabalhadores: atividade normativa da organização internacional do trabalho. Porto Alegre: Livraria do Advogado, 2007.

BRAMAN, Sandra. The Emergent Global Information Policy Regime. New York: Palgrave Macmillan, 2004.

DONNELLY, Jack. International human rights: a regime analysis. International Organization, New York, n.40 v.3, p.559-642, Sum.1986.

FROTA, Maria Guiomar da Cunha; BARBOSA NETO, Pedro Alves. Mediação institucional e processo socioinformacional de monitoramento dos direitos da criança no sistema mundial. DatagramaZero Revista de Ciência da Informação, v. 11, n. 6, dez., 2010. Disponível em:

http://www.dgz.org.br/dez10/Art 04.htm. Acesso em: 12 de jun. 2012.

FROHMANN, B. Taking information policy beyond information science: Applying the actor network theory. In: H. A. Olson, D. B.Ward (Eds.). ANNUAL CONFERENCE OF THE CANADIAN ASSOCIATION FOR INFORMATION SCIENCE, 23, 1995, Edmonton, Alberta. [Proceedings...] Edmonton, Alberta, 1995.

FROTA, Maria Guiomar da Cunha; BARBOSA NETO, Pedro Alves. Regimes de informação e regimes internacionais de direitos humanos: perspectivas teóricas e metodológicas. In: ENCONTRO NACIONAL DE PESQUISA EM PÓS-GRADUAÇÃO EM CIÊNCIA DA INFORMAÇÃO, 15, 2014, Belo Horizonte. [Anais...]. Belo Horizonte: Escola de Ciência da Informação da Universidade Federal de Minas Gerais, 2014.

KRASNER, Stephen D. Structural Causes and Regime Consequences: Regimes as Intervening Variables. International Organization, New York, v. 36, p. 185-205, Spring 1982.

HILTON, Margaret. Monitoring International Labor Standards: quality of information. Washington: The National Academies Press, 2003.

INTERNATIONAL LABOUR ORGANIZATION. Reports requested and replies to CEACR comments: C182 - worst forms of child labour convention, 1999.

em: 
http://www.ilo.org/dyn/normlex/en/f?p=NORMLEXPUB:14001:0::NO:140 01:P14001 INSTRUMENT ID:312327: NO Acesso em: 15 de jun. 2015.

MAGNANI, Maria Cristina Brasil; PINHEIRO, Marta Macedo Kerr. "Regime" e "Informação": a aproximação de dois conceitos e suas aplicações na Ciência da Informação. Liinc em Revista, Rio de Janeiro, v. 7, n. 2, p.593610, set. 2011.

ORGANIZAÇÃO INTERNACIONAL DO TRABALHO. Convenção n. 182: convenção sobre proibição das piores formas do trabalho infantil e ação imediata para sua eliminação. Brasília: OIT, 2000. Disponível em: http://www.oit.org.br/sites/all/ipec/download/conv 182.pdf. Acesso em: 10 de jun. 2015.

ORGANIZAÇÃO INTERNACIONAL DO TRABALHO. Declaração de Princípios e Direitos Fundamentais do Trabalho. Brasília: OIT, 1998. Disponível em: https://www.ilo.org/public/english/standards/declaration/declaration port uguese.pdf. Acesso em: 17 de out. 2018. 